\title{
Square Slot Antenna for Wide Circularly Polarized Bandwidth and Axial Ratio Beamwidth
}

\author{
Vijay Sharma (Assistant Professor, Department of Physics, Govt Mahila Engineering College, \\ Ajmer, India), \\ Tejpal Jhajharia* (Assistant Professor, Department of Electronics \& Communication Engineering, \\ School of Electrical, Electronics \& Communication Engineering, Manipal University Jaipur, India)
}

\begin{abstract}
The article proposes design investigation and experimental results of a coplanar waveguide (CPW) fed square slot antenna that gives wideband circular polarization. This circular polarization characteristic is achieved by embedding a square shape stub to left bottom corner and an L-shaped strip to the right upper corner of the slot. A high impedance bandwidth of $87.8 \%(3.6-9.0 \mathrm{GHz})$, a wide axial ratio bandwidth of $73.05 \%$ (4.2-9.0 GHz) and wide 3-dB axial ratio beamwidth of $90^{\circ}$ in the entire frequency range of interest are achieved with this antenna structure. To improve the 3-dB axial ratio bandwidth, three slots (two horizontal and one vertical) are scratched at the exterior periphery of the ground plane. These perturbation assemblies are accountable to excite orthogonal modes and help increase an axial ratio bandwidth. The designed antenna displays the constant and steady radiation patterns in the complete frequency range of concern. The overall dimension of the presented compact antenna is $0.24 \lambda \times 0.24 \lambda \times 0.01 \lambda$.
\end{abstract}

Keywords - Antenna radiation patterns; Gain; Slot antenna; Wideband; Wireless communication.

\section{INTRODUCTION}

In wireless communication, circularly polarized (CP) antenna is extensively popular on account of its capacity of anticipating polarization mismatch and adaptability of the orientation angle between receiving and transmitting antennas. In most of the communication system applications, it turns out to be very hard to deal with the alignment or orientation of the antenna [1], [2]. The CP radiations can be achieved when two orthogonal vectors (electric field) having the same amplitude and in phase quadrature (ninety-degree phase) superimpose. There are several techniques to achieve $\mathrm{CP}$ in printed antennas. Among these due to advantages of compact size, design simplicity and fabrication slot antennas are most popular for $\mathrm{CP}$ operations [3]. Though the problem is the narrow beamwidth and bandwidth (axial ratio / impedance), which limit the utilisation of such existing antennas. To address the problem of constrained beamwidth, researchers of impedance bandwidth $(I B W)$ and axial ratio bandwidth $(A R B W)$ have proposed various kinds of slots, structures, and shapes [4]-[6].
By and large, the adjustment in orthodox structure cannot guarantee high beamwidth and bandwidth (IBW/ARBW). Researchers working in the area of antenna engineering are probing for new techniques and methodology to solve this problem, without impacting additional antenna properties. A summary of the design methodology and results achieved by researchers to address the issue in recent times is the following.

A reconfigurable dual-band $\mathrm{CP}$ antenna for $\mathrm{C}$ band wireless system having an $A R B W$ of $4.5 \%(4.3-4.5 \mathrm{GHz})$ and $17.69 \%$ $(5.10-6.09 \mathrm{GHz})$ is realised by Jhajharia et al. [7], using PIN diode. However, the use of PIN diode makes the structure somewhat complex. In [8], Dwivedi et al. proposed a compact UWB antenna using defected ground technique and parasitic patch simultaneously. To achieve a UWB behaviour in the frequency range of 4.93-13.54 GHz, a U-shaped slot is etched in a rectangular patch in association with two symmetric square shape parasitic patches, followed by an asymmetrical hexagonal slot-loaded in the ground. The measurement result shows that fabricated antenna offers a radiation efficiency of $95 \%$ with a peak gain of $4 \mathrm{dBi}$. An $A R B W$ of $75.23 \%(2.67-5.89 \mathrm{GHz})$ is attained by the Birwal et al. [9], with a dual sense CP design modified with a P-shape dual-port. Two defected ground structures viz semi-circular and triangular slots are also etched in ground plane for this result. However, the large volume $(48 \mathrm{~mm} \times 48 \mathrm{~mm} \times 1.5 \mathrm{~mm})$ of the antenna is an issue. In [10], Nasimuddin et al. offered and validated with the measured result a novel asymmetric-microstrip antenna for wide-angle CP radiation for Global Navigation Satellite System (GNSS) application. The offered design consists of four small circularpatches of unequal radii at four corners of a square patch antenna. This small difference in radii of these circular patches helps in the generation of two orthogonal field components with a quadrature phase and the same amplitude for $\mathrm{CP}$ behaviour. To increase the 3 -dB $A R B W$ (up to $84.40 \%$ in the frequency range of $1.89-4.65 \mathrm{GHz}$ ) and beamwidth (more than $75^{\circ}$ ), Trinh-Van et al. [11] presented a crescent-shaped slot antenna. The designed antenna is energized by a twisted feeding line connected with a microstrip feed line of $50 \Omega$. A novel single feed dual-band CP antenna geometry consisting of two

"Corresponding author.

E-mail: tej.pal@jaipur.manipal.edu

(C)2021 Vijay Sharma, Tejpal Jhajharia.

This is an open access article licensed under the Creative Commons Attribution License

(http://creativecommons.org/licenses/by/4.0), in the manner agreed with Sciendo. 
perpendicular arms monopole with inclined edge DGS (an asymmetric T-shaped slot have a cross-slot) is proposed by Jhajharia et al. for the wireless applications systems operating in C-band [12].

In [13], Qin et al. proposed a longitudinal broadband CP antenna array having eight elements with nearly $100^{\circ}$ $3-\mathrm{dB} A R$ beamwidth and $17 \mathrm{dBi}$ gain in the horizontal plane for the second, third, and fourth-generation mobile communication systems. In [14], Ravikanti and Anjaneyulu proposed a compact circular patch $\mathrm{CP}$ antenna for a recent $5 \mathrm{G}$ application using a coaxial probe feed. Three semi-circular symmetric slits of radius $2.0 \mathrm{~mm}$ along $+\mathrm{x},-\mathrm{x}$ and $+\mathrm{y}$ axes in association with another asymmetric semi-circular slit of radius $2.9 \mathrm{~mm}$ along minus y-axis are etched to attain the CP. In [15], Jhajharia et al. proposed a wideband (102.04 \% IBW) CP antenna with $37.5 \%$ $A R B W$ consisting of a couple of two asymmetric meanderedshaped orthogonal arms and stubs in-ground and patch. The half power beam width $(H P B W)$ in the $\mathrm{XOZ}$ and $\mathrm{YOZ}$ planes are nearly $81.9^{\circ}$ and $91.4^{\circ}$, respectively. In [16], Li and Zhang proposed a small size $\left(0.42 \lambda_{0} \times 0.42 \lambda_{0} \times 0.16 \lambda_{0}\right)$ wide beam $\mathrm{CP}$ antenna useful for wideband wireless communication systems. This significant $H P B W$ of nearly $120^{\circ}$, wide $A R B W$ and $I B W$ is attained due to inverted L-shaped structures and defects in the ground. Recently to achieve the wide $H P B W$ and $I B W$, Yan et al. [17] proposed an umbrella-shaped CP antenna consisting of two couples of identical patch dipoles connected to an umbrella-shaped material (substrate). To increase the $H P B W$ further (more than $120^{\circ}$ ), a freeloading metallic ring is placed just on top of this material substrate.

This article is an extended version of the paper presented at MTTW'20, Riga, Latvia [18]. In this piece of work, the design (simulation), fabrication and investigation of a compact CPW fed square slot antenna are taken. The presented design comprises a symmetric L-shaped strip and three wide slots at the exterior periphery of the square shaped slot antenna. This structure gives a wide $3-\mathrm{dB} A R B W, 73 \%$ along with $87.8 \%$ $I B W$. A wide beamwidth (nearly $100^{\circ}$ ) throughout the frequency range is the key output of this design. In subsequent sections, the antenna design layout plan, analysis of results, and conclusion are deliberated.

\section{ANTENNA DESIGN AND ANALYSIS}

\section{A. Antenna Geometry}

The schematic design steps of the offered antenna structure are outlined in Fig. 1 $(\mathrm{a}-\mathrm{c})$. The antenna is designed, simulated and fabricated on a one side copper cladded, low-cost lossy FR4 substrate with the properties of relative permittivity $=4.4$, loss tangent $=0.025$ and substrate height $H=1.0 \mathrm{~mm}$. The substrate size actually represents the overall dimension of the antenna $(L \times W \times H)$. The dimension of the metallic square patch is $\left(L_{\mathrm{P}} \times W_{\mathrm{P}}\right)$. The co-planar waveguide fed technique is used to energize the square slot antenna. The feed line parameters viz the gap value ' $g$ ' and the width of the feed line $W_{\mathrm{f}}$ are calculated by applying the integral feed line calculator available in CST Microwave Studio v.17 [19].

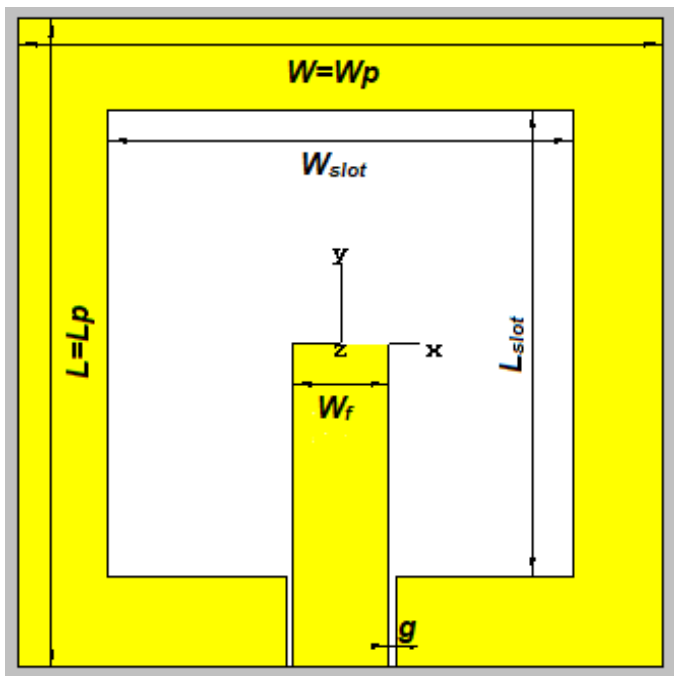

(a) Antenna-1

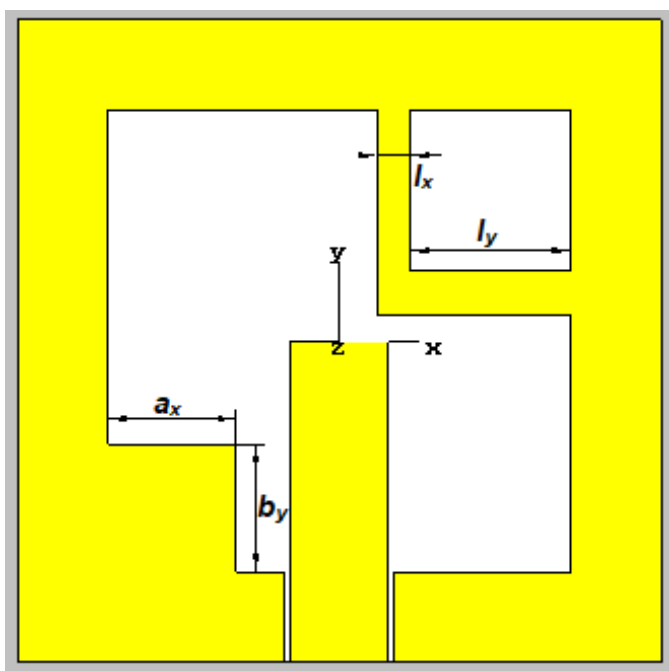

(b) Antenna-2

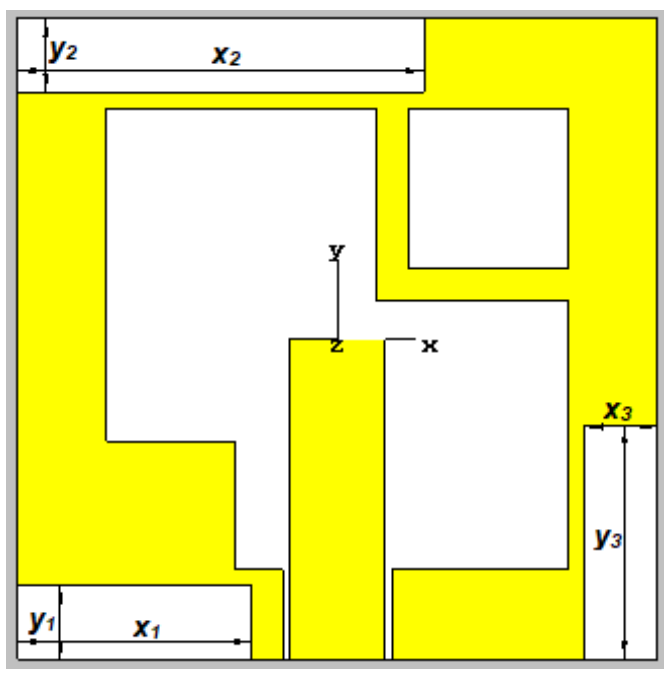

(c) Antenna-3

Fig. 1. Step-wise development of the prototype antenna. 
2021, vol. 17, no. 1

Further, the dimensions of various slots involved in final design are optimized with the help of parametric optimization process accessible in CST Microwave Studio v.17.

\section{B. Design Procedure}

In this part, the design technique of the proposed antenna is depicted with the help of three design stages. In the first step of the proposed design, a wide square slot of the optimized dimension $\left(L_{\text {slot }} \times W_{\text {slot }}\right)$ is etched in the metallic square patch (top surface of the substrate) that serves as the radiation aperture. The optimized location and size of feed line can control the coupling between radiating slot aperture and CPW feed line, which facilitates the impedance matching of Antenna-1 and enhances the impedance bandwidth [20]. Since this is a co-planar waveguide fed design, there is no metal conductor at the backside of the substrate (Fig. 1(a)).

To achieve circular polarization, the design of Antenna-1 is modified in the second step (Fig. 1(b)), by applying a symmetric L-strip having the optimized dimensions $\left(l_{x} \times l_{y}\right)$ along the $\mathrm{x}$-axis and $\mathrm{y}$-axis, which excite the orthogonal modes. A minor square patch of the optimized dimension $\left(a_{\mathrm{x}} \times b_{\mathrm{y}}\right)$ is also protruded at the lower-left corner of the slotted square, which also supports the orthogonal radiation modes.

To further enhance the circularly polarized bandwidth and to overlap with impedance bandwidth, the design of Antenna-2 is again modified in the third step (Fig. 1(c)). The square slot aperture is further modified by applying two horizontal slots and one vertical slot of the optimized dimensions $\left(x_{1} \times y_{1}\right)$, $\left(x_{2} \times y_{2}\right)$, and $\left(x_{3} \times y_{3}\right)$ are respectively etched at the lower-left corner, upper left corner and the lower right corner from the CPW ground plane radiator. The final design with all the optimized values is depicted in Fig. 2.

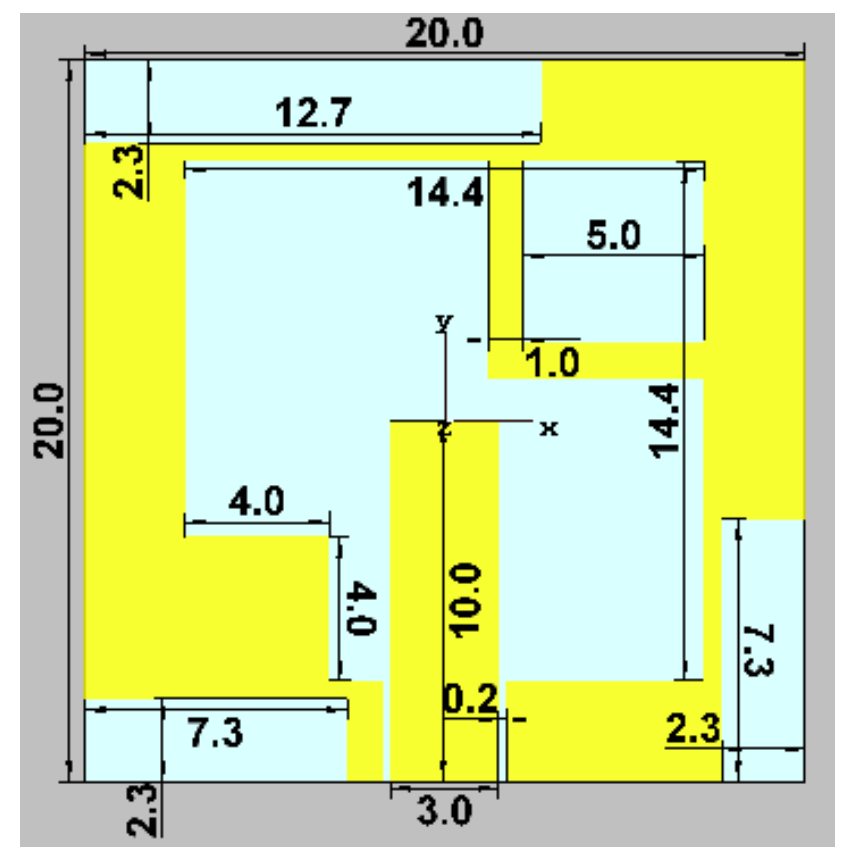

Fig. 2. Sketch of the offered CPW-fed square slot antenna (in mm).

Table I represents all the notations used in design along with their values.
TABLE I

Parameters of the Proposed CPW-Fed Square Slot AntenNA

\begin{tabular}{|c|c|c|c|}
\hline Parameter & Value, $\mathbf{m m}$ & Parameter & Value, $\mathbf{m m}$ \\
\hline$L=L_{\mathrm{p}}$ & 20 & $W=W_{\mathrm{p}}$ & 20 \\
\hline$L_{\text {slot }}$ & 14.4 & $W_{\text {slot }}$ & 14.4 \\
\hline$a_{\mathrm{x}} \times b_{\mathrm{y}}$ & 4.0 & $l_{x} \times l_{y}$ & $1.0 \times 6.0$ \\
\hline$x_{1} \times y_{1}$ & $7.3 \times 2.3$ & $x_{2} \times y_{2}$ & $12.7 \times 2.3$ \\
\hline$x_{3} \times y_{3}$ & $2.3 \times 7.3$ & $W_{\mathrm{f}}$ & 1.5 \\
\hline$g$ & 0.2 & $h$ & 1.0 \\
\hline
\end{tabular}

In this study, the main aim is to achieve the wide impedance bandwidth with good quality circular polarization, i.e., wide $A R B W$ and wide beamwidth. For the continuity of the text, a brief definition of the terms fractional $B W, A R$ and $A R B W$ used in this article is as follows.

The percentage bandwidth (fractional bandwidth) can be calculated by using Eq. (1).

$$
B W_{\mathrm{p}}=\left(B W / f_{\mathrm{c}}\right) \times 100 \%
$$

Here, $B W$ is the nominal bandwidth defined as $B W=\left(f_{\mathrm{h}}-f_{\mathrm{l}}\right)$ and the central frequency is $f_{\mathrm{c}}=\left(f_{\mathrm{h}}+f_{1}\right) / 2$. Here, $f_{1}$ and $f_{\mathrm{h}}$ are the minimum and maximum frequency at $-10 \mathrm{~dB}$, respectively.

The axial ratio $(A R)$ value, which is a measure of circular polarization, is the ratio of the major and minor semi-axes of the polarization ellipse and expressed as [21]:

$$
A R(\mathrm{~dB})=20 \log \left(E_{x 0} / E_{y 0}\right)
$$

Here, $E_{x 0}$ and $E_{y 0}$ characterise the extreme magnitudes of the electric field in the directions of the $x$-axis and $y$-axis, respectively.

For the axial ratio value, $A R=1$ or $0 \mathrm{~dB}$, a pure $\mathrm{CP}$ behaviour is realised. However, in practice, it is a very challenging task to get this value. To simplify this process, a range of frequency $\left(f_{\mathrm{h}}-f_{\mathrm{l}}\right)$ up to which $A R \leq 3 \mathrm{~dB}$ is taken to compute circular polarization for practical applications. The $3-\mathrm{dB} A R B W$ is defined as:

$$
A R B W=\left(f_{\mathrm{h}}-f_{1}\right) / f_{\mathrm{c}} .
$$

\section{Analysis of Evolution Steps}

This section describes the analysis of the evolution process of antenna design shown in Fig. 1(a-c). Step 1 (Antenna-1) is a conventional CPW fed square slotted antenna that gives a wide impedance bandwidth with linear polarization (zero $A R B W$ since axial ratio value $>6 \mathrm{~dB}$ ). The $\mathrm{S}_{11}$ and axial ratio variation of 'Antenna-1' is shown in Fig. 3 and Fig. 4, respectively. A wide $I B W$ range of $3.92-6.85 \mathrm{GHz}(54.5 \%$ concerning centre frequency) is attained.

In Step 2 (Antenna-2), to achieve the wide $A R B W$ and wide $I B W$, following [22], a square patch and an L-shaped grounded strip structure of dimension $\left(a_{x} \times b_{y}\right)$ and $\left(l_{x} \times l_{y}\right)$ are loaded at the lower-left corner and upper right corner of the square slot, respectively. $S_{11}$ and axial ratio variation of 'Antenna-2' are shown in Fig. 3 and Fig. 4, respectively. It is perceived that the 
antenna is now showing circularly polarized behaviour with $3-\mathrm{dB} A R B W$ of $18.8 \%(7.7-9.31 \mathrm{GHz})$ and the $I B W$ is $82.7 \%$ (3.78-9.1 GHz), concerning centre frequency of $6.43 \mathrm{GHz}$. This L-shaped strip and square patch act as the perturbation structures and are responsible for this enhanced performance. These structures modify the path of the magnetic currents in the slots in such a manner that two orthogonal resonant modes with equal amplitude and a quarter phase difference can be excited.

In Step 3, to further improve the $A R B W$ of 'Antenna-2', following [23], three slots are introduced on the exterior periphery of the grounded square to alter the current path for the desired result. Two horizontal slots of dimensions $\left(x_{1} \times y_{1}\right)$ and $\left(x_{2} \times y_{2}\right)$ are etched in the lower and upper left corners, respectively, along with one vertical slot of dimension $\left(x_{3} \times y_{3}\right)$ in the lower right corner. In the final design 'Antenna-3', these embedded slots are predominantly responsible for the rotation of the current vector in such a way that give rise to an extended $A R B W$ of $73 \%(4.17-8.97 \mathrm{GHz})$ and nearly $87.8 \%(3.56-$ $9.14 \mathrm{GHz}),-10 \mathrm{~dB} I B W$.

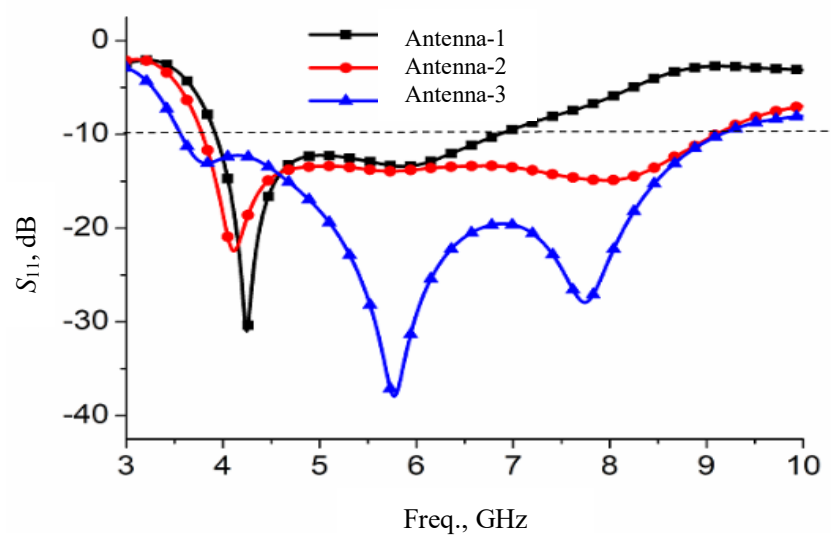

Fig. 3. $S_{11}$ variation with frequency for Antennas 1, 2 and 3.

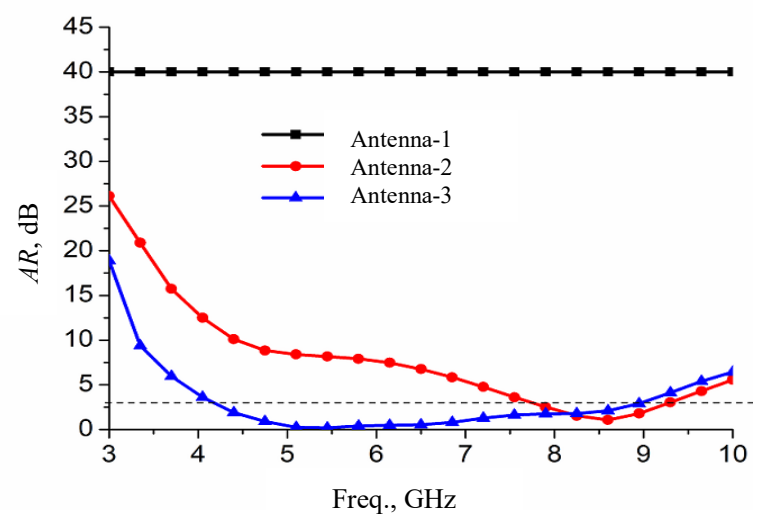

Fig. 4. Variation of $A R$ value with frequency for Antennas 1, 2 and 3.

\section{PARAMETRIC OPTIMIZATION FOR DIFFERENT PARAMETERS}

In this segment, to achieve the best value of $A R B W$ and $I B W$, extensive simulations are conceded out for variation of axial ratio and $S_{11}$, using the CST. A parametric analysis of the various antenna design factors is performed to investigate the optimised value. Individual effects of these parameters (such as slot length and width) for all the three slots at the perimeter of the square patch are optimised to acquire the finest axial ratio and $I B W$. The height of the substrate is also optimised for the best value of $A R$ along with $I B W$. These parameters such as substrate height ' $H$ ', the dimensions of different slots $\left(x_{1}, y_{1}, x_{2}\right.$, $\left.y_{2}, x_{3}, y_{3}\right)$, as shown in Fig. 1(c), create a great influence on antenna performance. The final value of all these parameters is given in Fig. 2.

\section{A. Effect of the Substrate Height ' $H$ '}

Figure $5(\mathrm{a} \& \mathrm{~b})$ shows the effect of substrate height on reflection coefficient and axial ratio with varying frequency. It is a proven fact that $I B W$ increases with increasing ' $H$ ' value due to a decrease in the quality factor. However, it degrades the $A R B W$. For $H=0.5 \mathrm{~mm}$ the enhanced $A R B W(4.1-10 \mathrm{GHz})$ is attained with the shift in $I B W(4.3-9.8 \mathrm{GHz})$ towards a higher frequency side. For $H=1.0 \mathrm{~mm}$ the $A R B W$ is in the range of $4.2-9.0 \mathrm{GHz}$ and $I B W$ is in the range of 3.5-9.1 GHz. For $H=1.5 \mathrm{~mm}$ the $A R B W$ is in the range of $4.05-8.2 \mathrm{GHz}$ and $I B W$ is in the range of $3.4-8.8 \mathrm{GHz}$. An optimised value of $H=1.0 \mathrm{~mm}$ is chosen for analysis. As per the application, the value of $H$ can be selected.

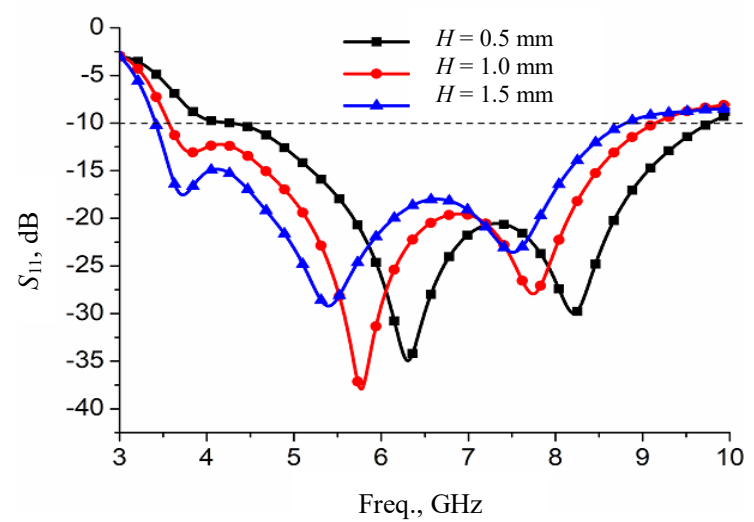

(a)

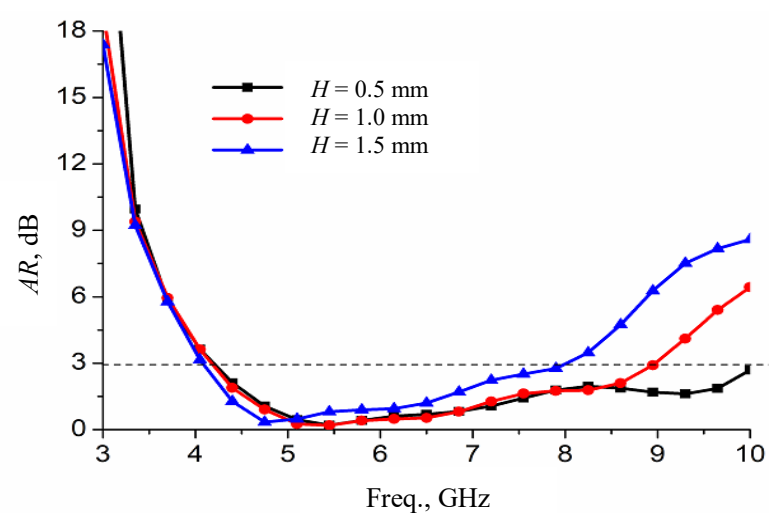

(b)

Fig. 5. Effect of ' $H$ ' on impedance bandwidth and axial ratio.

\section{B. Effect of $x_{1}$}

Figure $6(\mathrm{a} \& \mathrm{~b})$ displays the influence of $x_{1}$ (the dimension along the x-axis for the first slot) on $S_{11}$ and $A R$. Increasing the value of $x_{1}$, the lower edge frequency in the $S_{11}$ curve shifts towards a higher side, whereas in $A R$ curve it swings to a low frequency side. It is observed that for $x_{1}=2.7 \mathrm{~mm}$, the 
maximum $I B W$ and $A R B W$ along with minimum $A R$ value are achieved.

\section{Effect of $y_{1}$}

Figure $7(\mathrm{a} \& \mathrm{~b})$ displays the influence of $y_{1}$ (the dimension along the y-axis for the first slot) on $S_{11}$ and $A R$. With the increasing value of $y_{1}$ in $S_{11}$ curve, it is observed that there is no effect on lower edge frequency; however, upper edge frequency shifts to a higher frequency value and gives rise to $I B W$. Also in this situation, a lower edge of $A R$ value is shifting to a higher frequency that restricts the $A R B W$. Thus, a median value of $y_{1}=7.7 \mathrm{~mm}$ is taken for fabrication purpose.

\section{Effect of $x_{2}$}

Figure $8(\mathrm{a} \& \mathrm{~b})$ displays the influence of $x_{2}$ (the dimension along the x-axis for slot 2) on $S_{11}$ and $A R$. It is observed that for the negative value of $x_{2}$ the maximum $I B W$ is achieved; however, in this situation the $A R B W$ decreases. Increasing the value of $x_{2}$, the maximum $A R B W$ and $I B W$ are attained at $2.7 \mathrm{~mm}$. Beyond this value again the $A R B W$ decreases but this does not affect much the $I B W$.

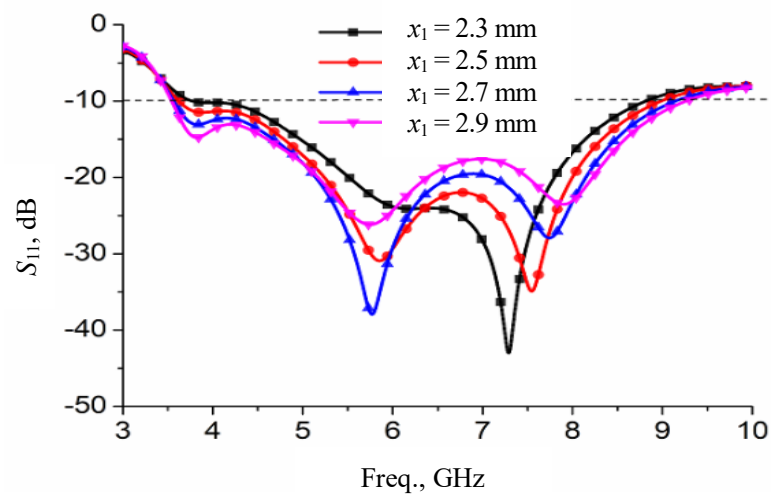

(a)

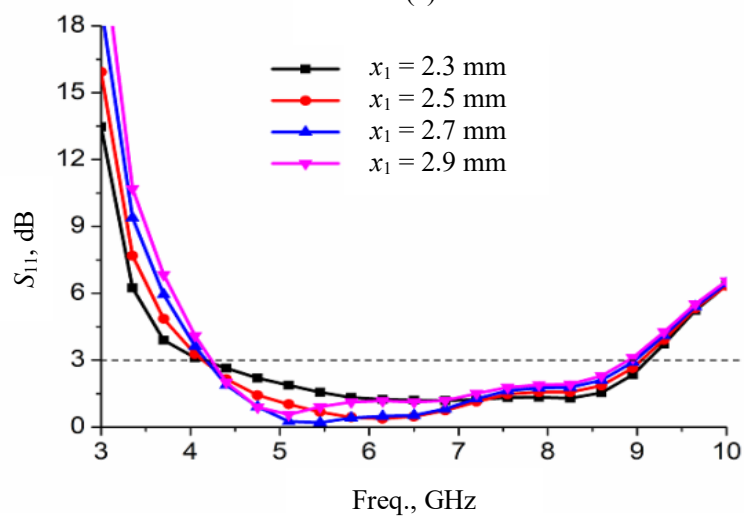

(b)

Fig. 6. Effect of ' $x_{1}$ ' on impedance bandwidth and axial ratio.

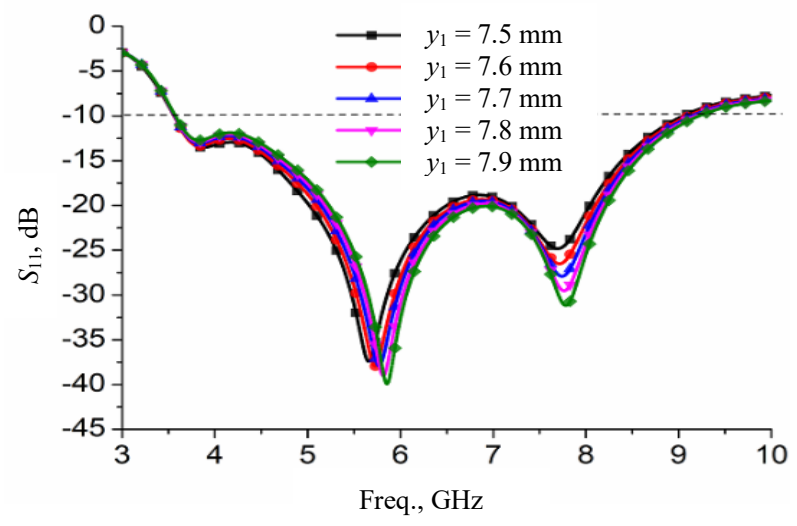

(a)

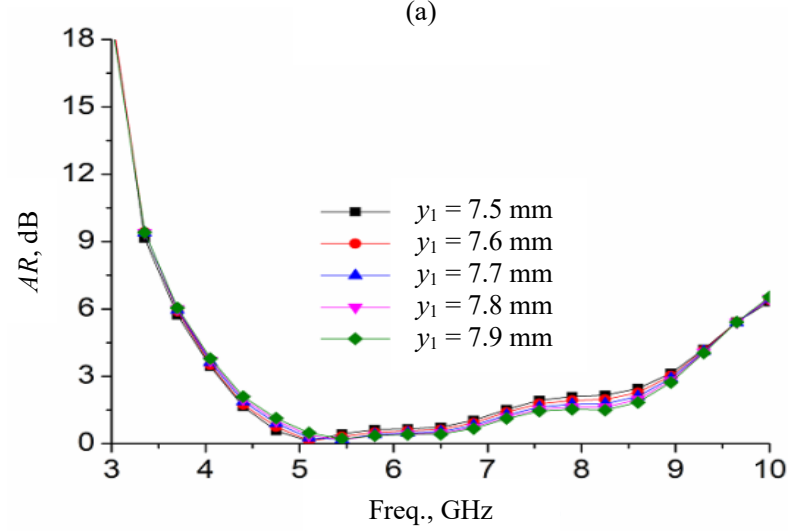

(b)

Fig. 7. Effect of ' $y_{1}$ ' on impedance bandwidth and axial ratio.

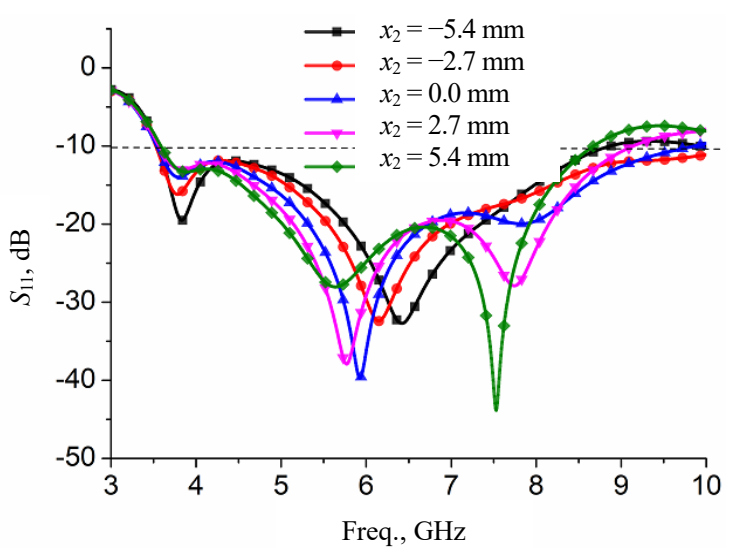

(a)

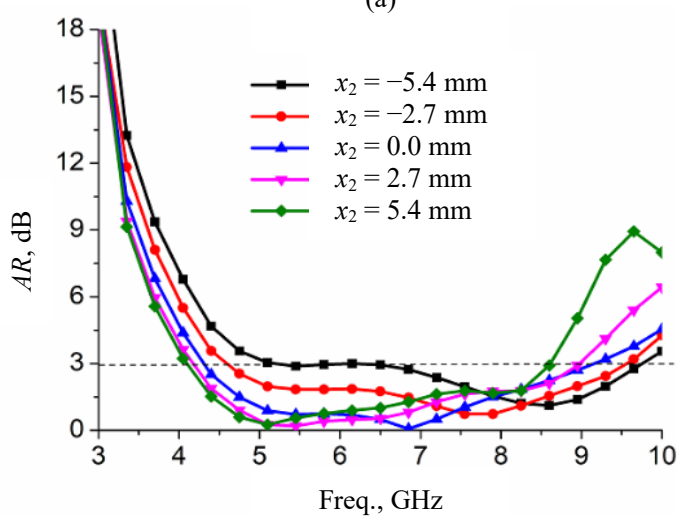

(b)

Fig. 8. Effect of ' $x_{2}$ ' on impedance bandwidth and axial ratio. 


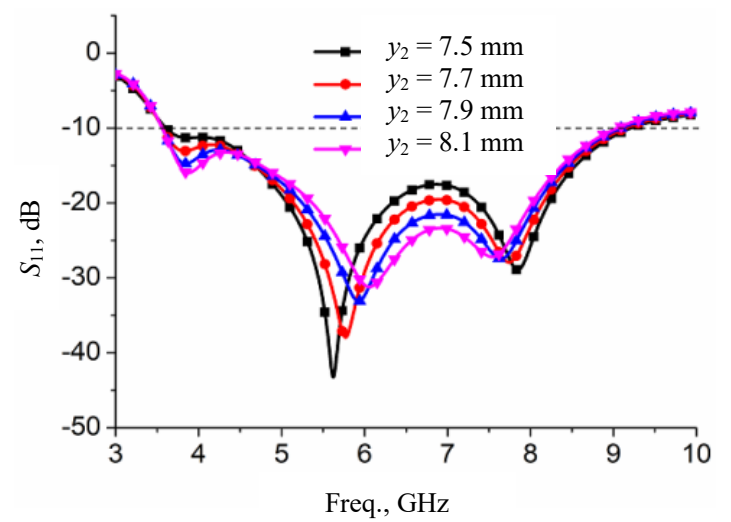

(a)

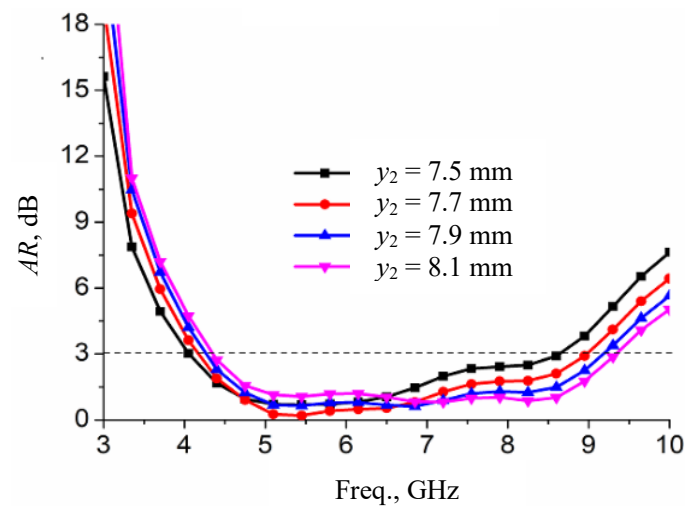

(b)

Fig. 9. Effect of ' $y_{2}$ ' on impedance bandwidth and axial ratio.

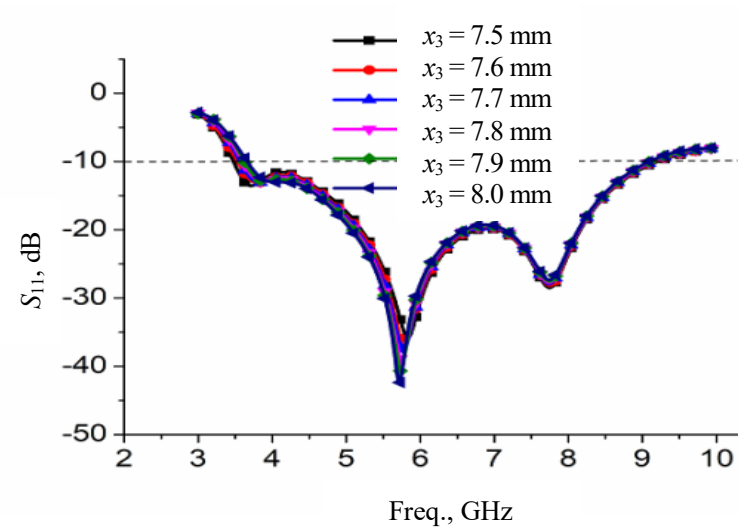

(a)

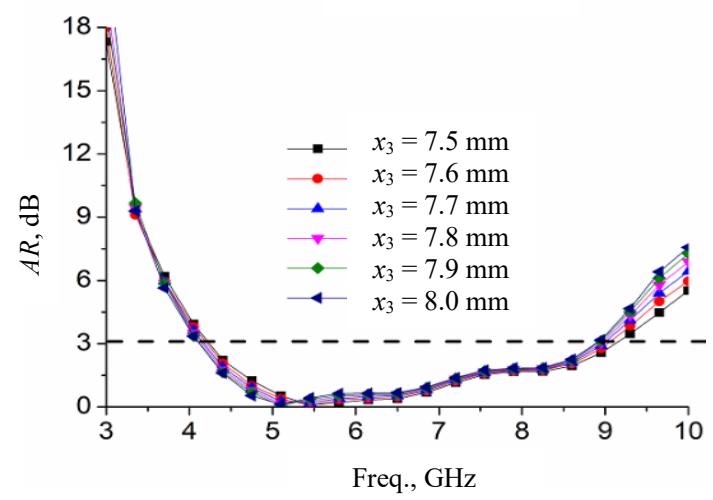

(b)

Fig. 10. Effect of ' $x_{3}$ ' on impedance bandwidth and axial ratio.

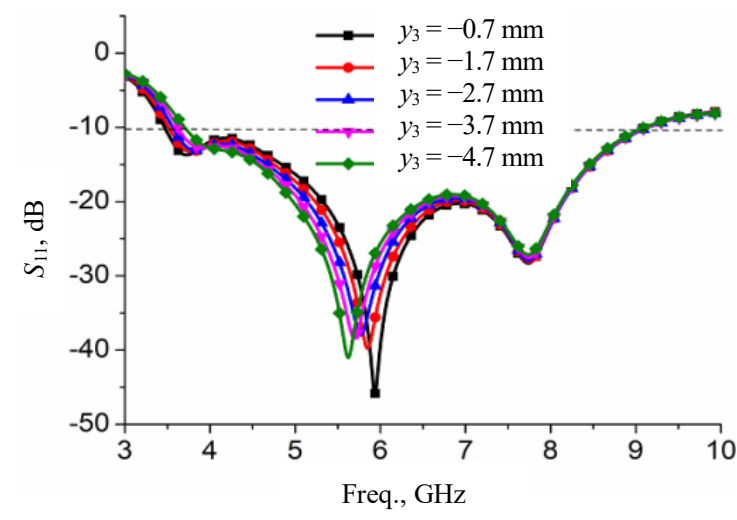

(a)

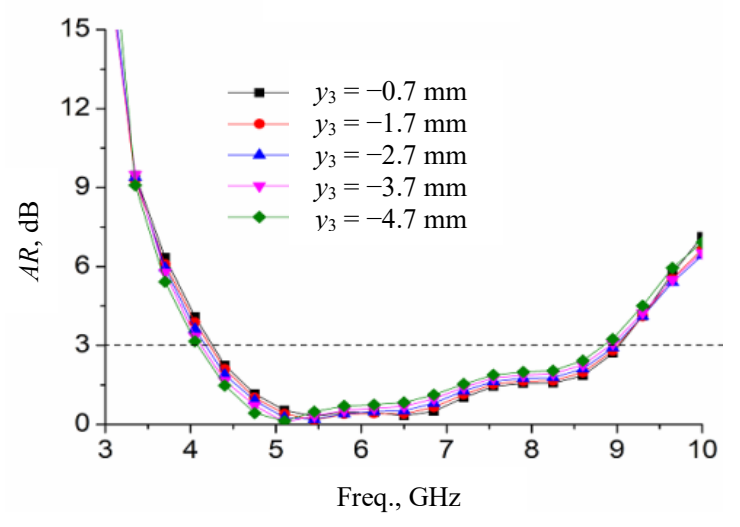

(b)

Fig. 11. Effect of ' $y_{3}$ ' on impedance bandwidth and axial ratio.

\section{E. Effect of $y_{2}$}

Figure $9(\mathrm{a} \& \mathrm{~b})$ displays the influence of $y_{2}$ (the dimension along the y-axis for slot 2) on $S_{11}$ and $A R$. It is observed for a larger value of $y_{2}$ the highest $I B W$ is seeming but the $A R B W$ reduces in this situation. On the other hand, for a lower value of $y_{2}$, the $A R$ curve shifts to a lower frequency and gives a larger value of $A R B W$. Thus, an optimised value $y_{2}=7.7 \mathrm{~mm}$ is chosen because for this value a good purity $\mathrm{CP}$ behaviour is attained.

\section{F. Effect of $x_{3}$}

Figure $10(\mathrm{a} \& \mathrm{~b})$ displays the effect of $x_{3}$ (the dimension along the x-axis for slot 3 ) on $S_{11}$ and $A R$. It is perceived that with growing value of $x_{3}$, the $I B W$ reduces as a lower edge frequency shifts towards higher frequency. The maximum $I B W$ is achieved for $x_{3}=7.5 \mathrm{~mm}$; however, for this case, the $A R B W$ is not the maximum. An optimised value of $x_{3}=7.7 \mathrm{~mm}$ is taken for fabrication purposes as it gives boosted $A R B W$ and $I B W$.

\section{G. Effect of $y_{3}$}

Figure 11(a\&b) displays the effect of $y_{3}$ (the dimension along the y-axis for slot 3) on $S_{11}$ and $A R$. It observed that increasing the value of $\mathrm{y}_{3}$ no effect on upper edge frequency in $\mathrm{S}_{11}$ curve is observed; however, a lower edge frequency swings to higher frequency. On the contrary, in the $A R$ curve the upper edge frequency swings to a lower frequency, and $3-\mathrm{dB} A R$ value increases. Thus the $3-\mathrm{dB} A R B W$ degrades. An optimum value of $y_{3}=2.7 \mathrm{~mm}$ is taken for fabrication. 


\section{ANALYSIS OF CP MECHANISM}

To realise the operating principle of the $\mathrm{CP}$ radiation mechanism, the asymmetry in design is introduced by inserting slots at the corners of the proposed antenna, to produce two orthogonal components with a $90^{\circ}$ phase shift and the same magnitude. The surface-current density distributions (computer-generated) at the different instant of the time/phase $\omega t=0^{\circ}, 90^{\circ}, 180^{\circ}$ and $270^{\circ}$ at two frequencies of $5.2 \mathrm{GHz}$ and $5.8 \mathrm{GHz}$, respectively, are displayed in Fig. 12(a-d) and Fig. 13(a-d). From these figures, it is obvious that the current vectors are rotating in a clockwise direction in the feed and upper ground plane, including L-shaped strip. As the phase of excitation grows, the outcomes confirm the left-hand polarization rotation in the upper half-sphere and the current vectors in both sides of the ground plane near the feed-line are rotating in anti-clockwise direction, which confirms right hand circular polarization in the lower half sphere for the entire axial ratio bandwidth.

The same is explained for the entire frequency range in Fig. 14(a\&b) and Fig. 15(a\&b) separately, in both principle radiating planes. The $3-\mathrm{dB} A R$ beamwidth of the offered antenna for the entire frequency range is plotted in Fig. 14 and Fig. 15, which show that the antenna has more than $90^{\circ}$ beamwidth in both radiating planes. Table II shows 3-dB angular width and 3-dB $A R$ beamwidth of the LHCP and RHCP for both radiating planes.

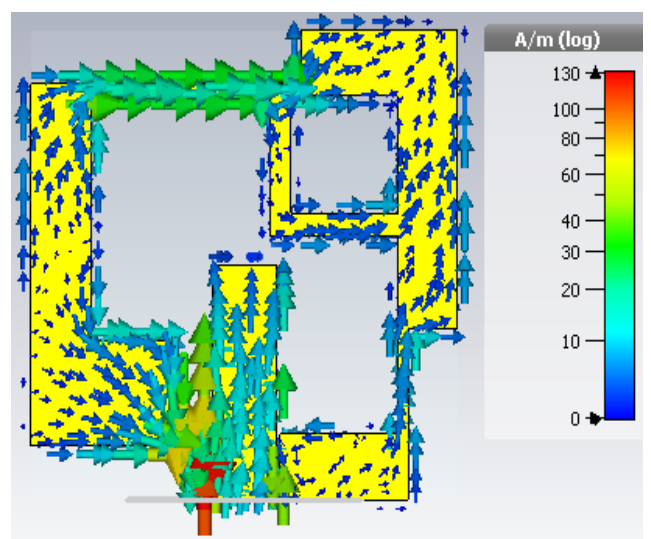

(a)

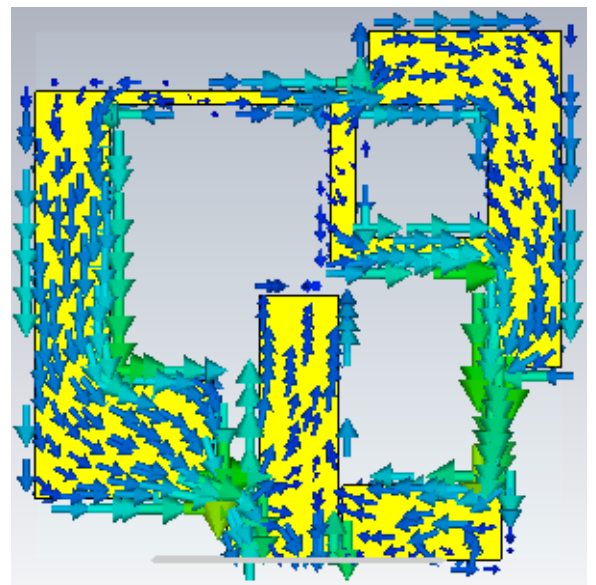

(b)

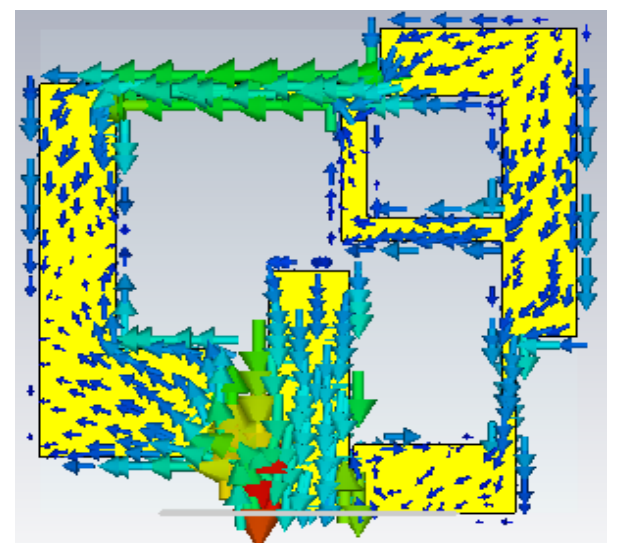

(c)

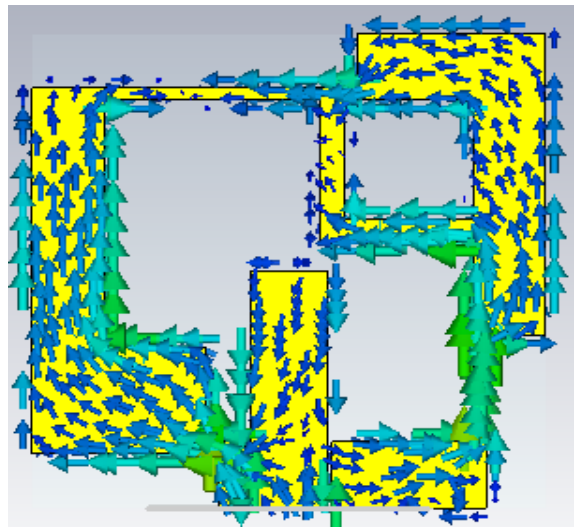

(d)

Fig. 12. Computer-generated surface current spreading at $5.2 \mathrm{GHz}$ (a) $0^{\circ}$; (b) $90^{\circ}$; (c) $180^{\circ}$ and (d) $270^{\circ}$.

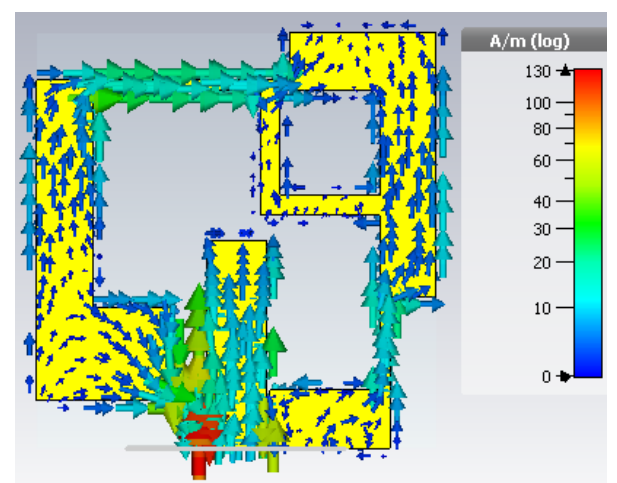

(a)

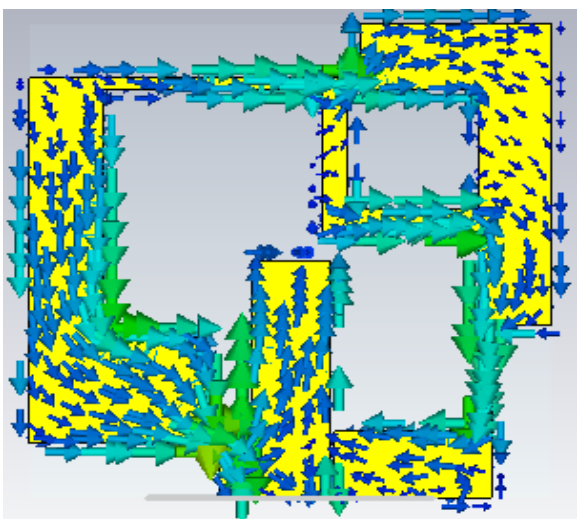

(b) 


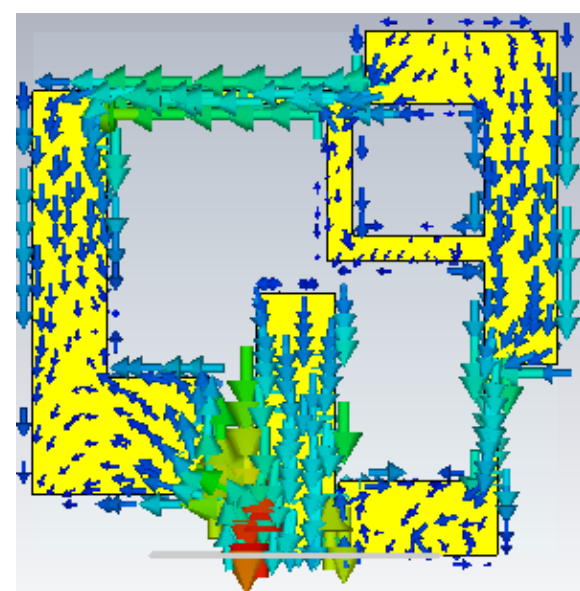

(c)

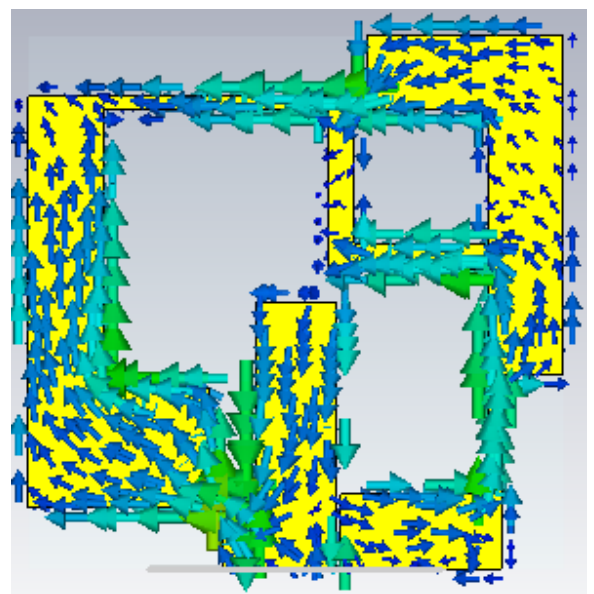

(d)

Fig. 13. Computer-generated surface current spreading at $5.8 \mathrm{GHz}$ (a) $0^{\circ}$; (b) $90^{\circ}$; (c) $180^{\circ}$ and (d) $270^{\circ}$.

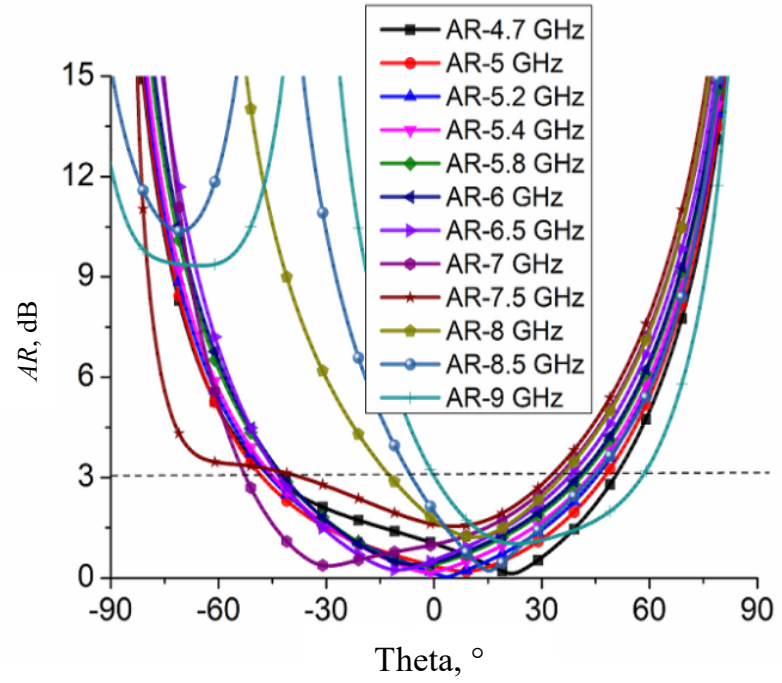

(a)

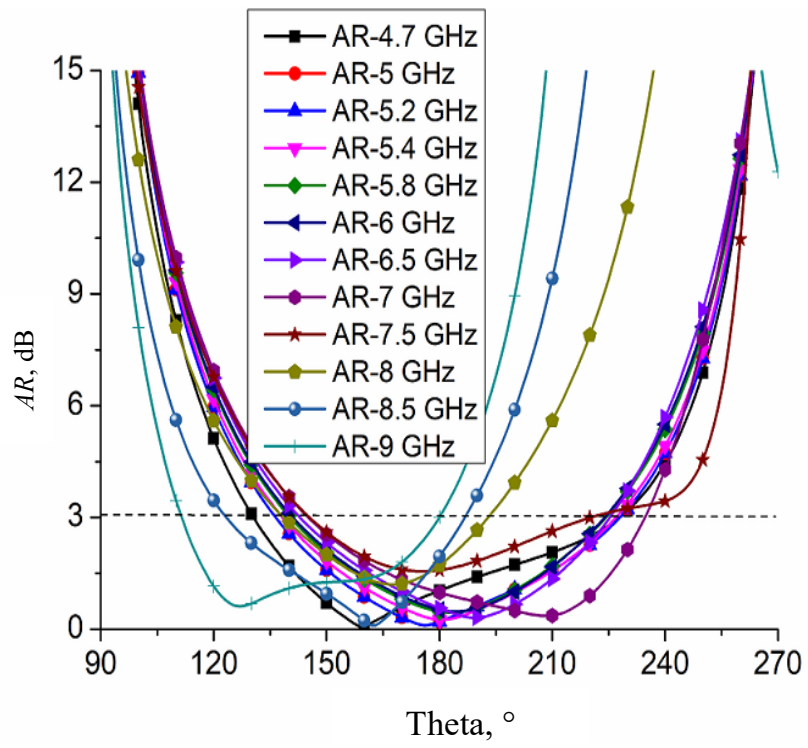

(b)

Fig. 14. $A R$ at $\phi=0^{\circ}$ : (a) LHCP in the $x z$-plane and (b) RHCP in the $y z$-plane.

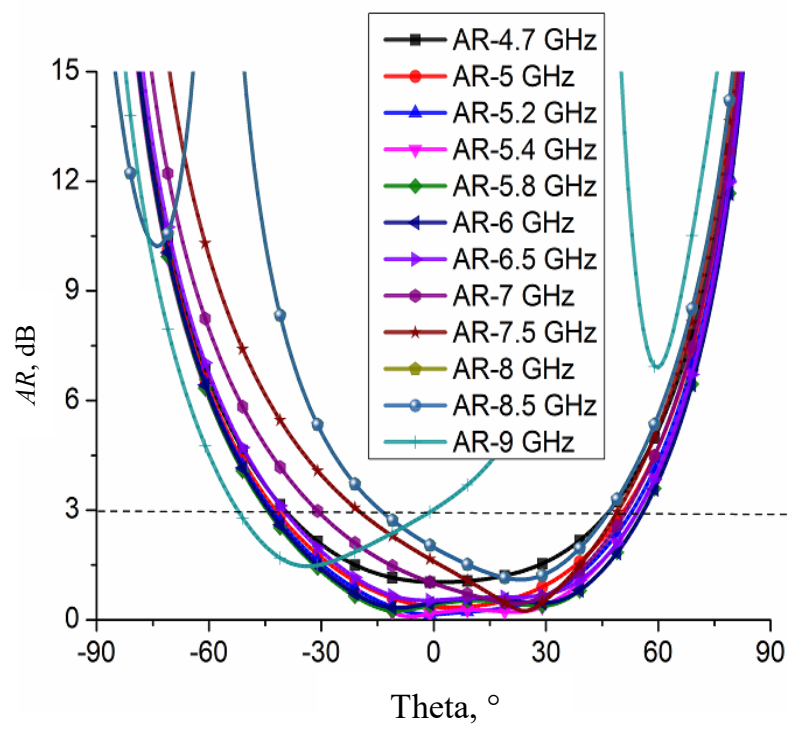

(a)

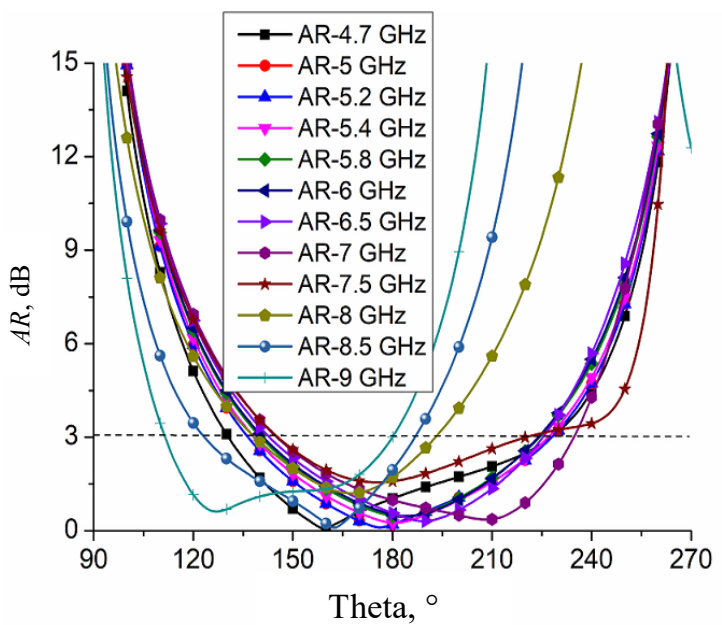

(b)

Fig. 15. $A R$ at $\phi=90^{\circ}$ : (a) LHCP in the $x z$-plane and (b) RHCP in the $y z$-plane. 
TABLE II

3-DB ANGULAR WIDTH AND $A R$ BEAMWIDTH

\begin{tabular}{|c|c|c|c|c|c|}
\hline \multirow[b]{2}{*}{$\begin{array}{l}\text { Freq., } \\
\text { GHz }\end{array}$} & \multirow[b]{2}{*}{$\underset{\circ}{\phi}$} & \multicolumn{2}{|c|}{$\begin{array}{c}\text { LHCP in } \\
\text { upper hemisphere }\end{array}$} & \multicolumn{2}{|c|}{$\begin{array}{c}\text { RHCP in } \\
\text { lower hemisphere }\end{array}$} \\
\hline & & $\begin{array}{c}\text { 3-dB } \\
\text { Angular } \\
\text { width }\end{array}$ & $\begin{array}{c}\text { 3-dB } A R \\
\text { Beamwidth }\end{array}$ & $\begin{array}{l}\text { 3-dB } \\
\text { Angular } \\
\text { width }\end{array}$ & $\begin{array}{c}\text { 3-dB } A R \\
\text { Beamwidth }\end{array}$ \\
\hline \multirow{2}{*}{4.4} & 0 & $108.2^{\circ}$ & $93^{\circ}$ & $101.8^{\circ}$ & $97^{\circ}$ \\
\hline & 90 & $108.2^{\circ}$ & $78^{\circ}$ & $108^{\circ}$ & $76^{\circ}$ \\
\hline \multirow{2}{*}{4.7} & 0 & $101.1^{\circ}$ & $96^{\circ}$ & $101.3^{\circ}$ & $98^{\circ}$ \\
\hline & 90 & $106.2^{\circ}$ & $87^{\circ}$ & $106.4^{\circ}$ & $87^{\circ}$ \\
\hline \multirow{2}{*}{5.0} & 0 & $100.1^{\circ}$ & $96^{\circ}$ & $100.1^{\circ}$ & $86^{\circ}$ \\
\hline & 90 & $103.8^{\circ}$ & $94.5^{\circ}$ & $104.0^{\circ}$ & $85^{\circ}$ \\
\hline \multirow{2}{*}{5.2} & 0 & $99.4^{\circ}$ & $90^{\circ}$ & $99.5^{\circ}$ & $94^{\circ}$ \\
\hline & 90 & $102.4^{\circ}$ & $96^{\circ}$ & $106.6^{\circ}$ & $99^{\circ}$ \\
\hline \multirow{2}{*}{5.4} & 0 & $98.5^{\circ}$ & $88^{\circ}$ & $98.3^{\circ}$ & $89^{\circ}$ \\
\hline & 90 & $100.9^{\circ}$ & $100^{\circ}$ & $101.2^{\circ}$ & $102^{\circ}$ \\
\hline \multirow{2}{*}{5.6} & 0 & $96.9^{\circ}$ & $86^{\circ}$ & $97^{\circ}$ & $85^{\circ}$ \\
\hline & 90 & $99.6^{\circ}$ & $100^{\circ}$ & $100^{\circ}$ & $92^{\circ}$ \\
\hline \multirow{2}{*}{6.0} & 0 & $93.9^{\circ}$ & $82^{\circ}$ & $94.1^{\circ}$ & $84^{\circ}$ \\
\hline & 90 & $97^{\circ}$ & $100.5^{\circ}$ & $97.6^{\circ}$ & $103^{\circ}$ \\
\hline \multirow{2}{*}{6.4} & 0 & $90.8^{\circ}$ & $80^{\circ}$ & $91.1^{\circ}$ & $83^{\circ}$ \\
\hline & 90 & $95.4^{\circ}$ & $97.5^{\circ}$ & $95.9^{\circ}$ & $101.1^{\circ}$ \\
\hline \multirow{2}{*}{7.2} & 0 & $83.9^{\circ}$ & $92.2^{\circ}$ & $84.9^{\circ}$ & $95^{\circ}$ \\
\hline & 90 & $92.6^{\circ}$ & $78^{\circ}$ & $93^{\circ}$ & $79^{\circ}$ \\
\hline \multirow{2}{*}{7.8} & 0 & $77.8^{\circ}$ & $49.9^{\circ}$ & $79.7^{\circ}$ & $66^{\circ}$ \\
\hline & 90 & $88.8^{\circ}$ & $68^{\circ}$ & $88.8^{\circ}$ & $76^{\circ}$ \\
\hline \multirow{2}{*}{8.5} & 0 & $70.9^{\circ}$ & $50.4^{\circ}$ & $72.9^{\circ}$ & $64^{\circ}$ \\
\hline & 90 & $83.2^{\circ}$ & $61^{\circ}$ & $82.5^{\circ}$ & $65^{\circ}$ \\
\hline \multirow{2}{*}{9.0} & 0 & $76.9^{\circ}$ & $47^{\circ}$ & $77.4^{\circ}$ & $53^{\circ}$ \\
\hline & 90 & $67^{\circ}$ & $57^{\circ}$ & $69^{\circ}$ & $70^{\circ}$ \\
\hline
\end{tabular}

\section{DISCUSSION ON EXPERIMENTAL RESULTS}

The fabricated prototype antenna is displayed in Fig. 16 and the measurement of $S_{11}$, axial ratio and gain for this antenna is shown in Fig. 17 and Fig. 18, respectively, that validate the offered design. The measured and simulated outcomes offer the $I B W$ of $6.4 \mathrm{GHz}(3.6-9.0 \mathrm{GHz})$, as shown in Fig. 17, axial ratio bandwidth of $5.8 \mathrm{GHz}(4.2-9.0 \mathrm{GHz})$ and a realised peak gain (maximum) of $4.4 \mathrm{dBic}$ over the $A R B W$ as shown in Fig. 18. The measured outcomes are in acceptable agreement with the simulated results. The simulated and measured radiation patterns at $\phi=0^{\circ}$ and $\phi=90^{\circ}$ planes for two resonant frequencies of $5.2 \mathrm{GHz}$ and $5.8 \mathrm{GHz}$ individually are shown in Fig. 19 and Fig. 20. The suggested antenna results depict a wide 3 -dB LHCP, $A R$ beamwidth of $90^{\circ}$ (in the $x z$-plane) and $96^{\circ}$ (in the $y z$-plane) and a wide RHCP $A R$ beamwidth of $94^{\circ}$ (in the $x z$-plane) and $99^{\circ}$ (in the $y z$-plane), respectively, at $5.2 \mathrm{GHz}$ as shown in Fig. 19. Also at frequency of $5.8 \mathrm{GHz}$, a wide $3-\mathrm{dB}$ LHCP $A R$ beamwidth of $90^{\circ}$ (in the $x z$-plane) and $96^{\circ}$ (in the $y z$-plane) and a wide RHCP $A R$ beamwidth of $92^{\circ}$ (in the $x z$-plane) and $89^{\circ}$ (in the $y z$-plane) are observed (see Fig. 20). In conclusion, over and above $90^{\circ}$ beamwidth is achieved by the offered antenna design.

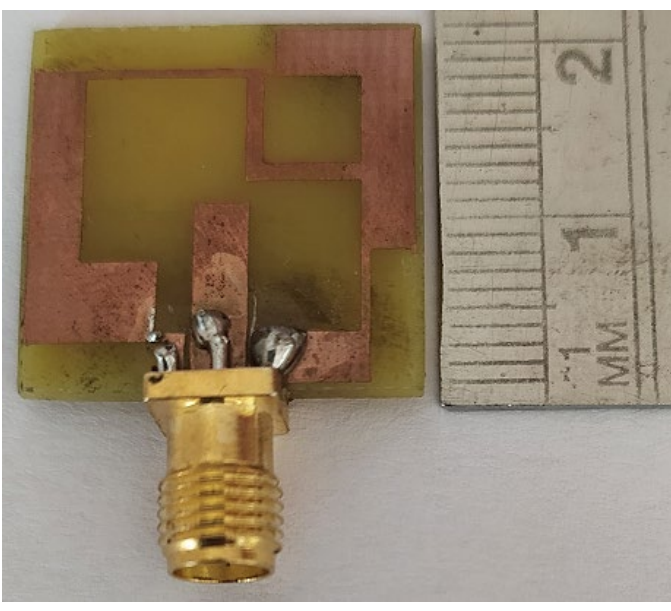

Fig. 16. Photograph of fabricated prototype antenna.

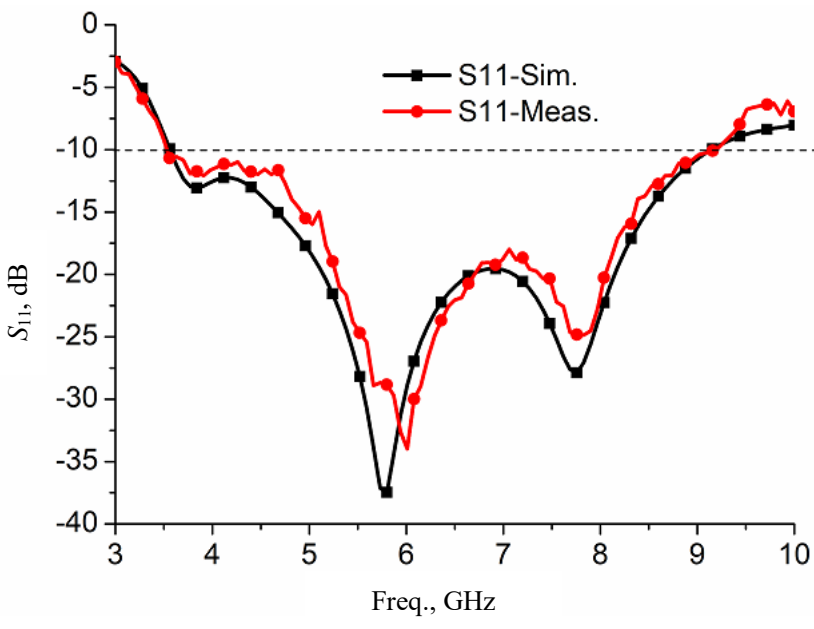

Fig. 17. Measured and simulated $S_{11}$ of fabricated prototype antenna.

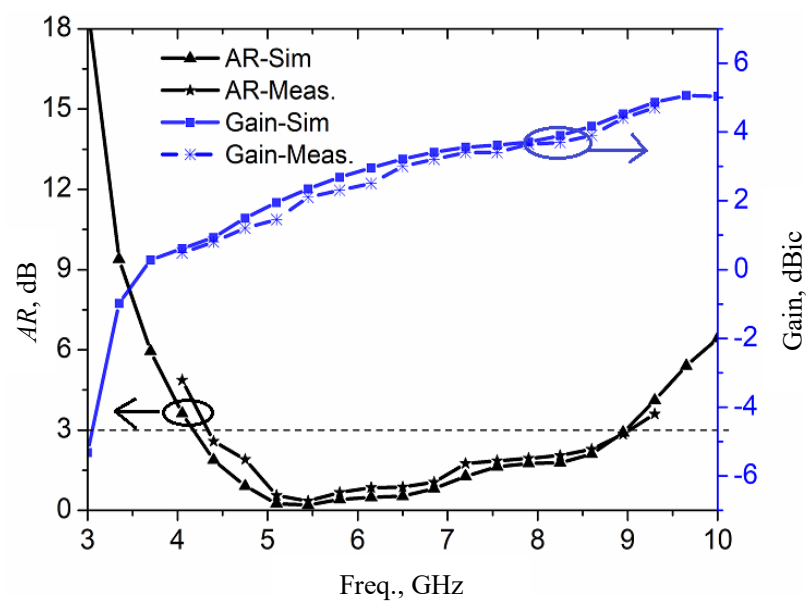

Fig. 18. Measured and simulated $A R$ and gain of fabricated antenna. 
2021, vol. 17, no. 1

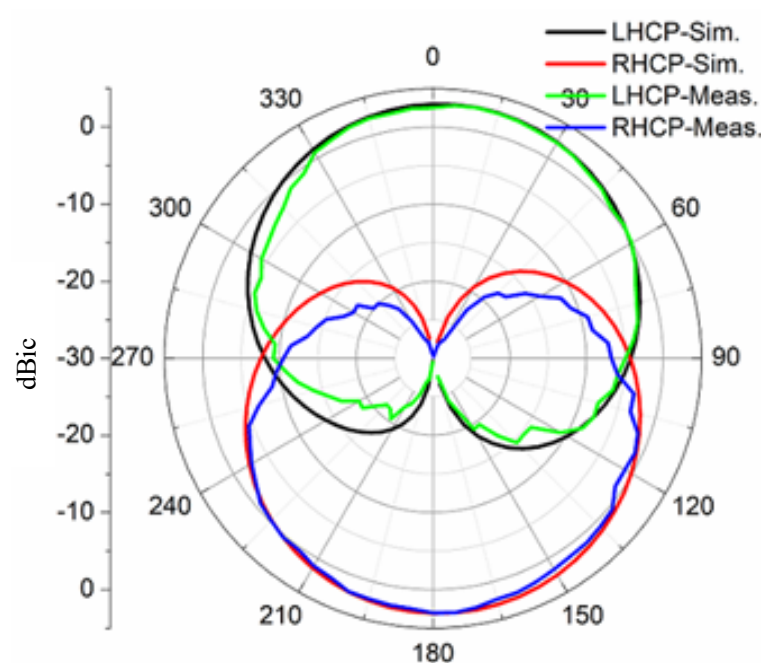

(a)

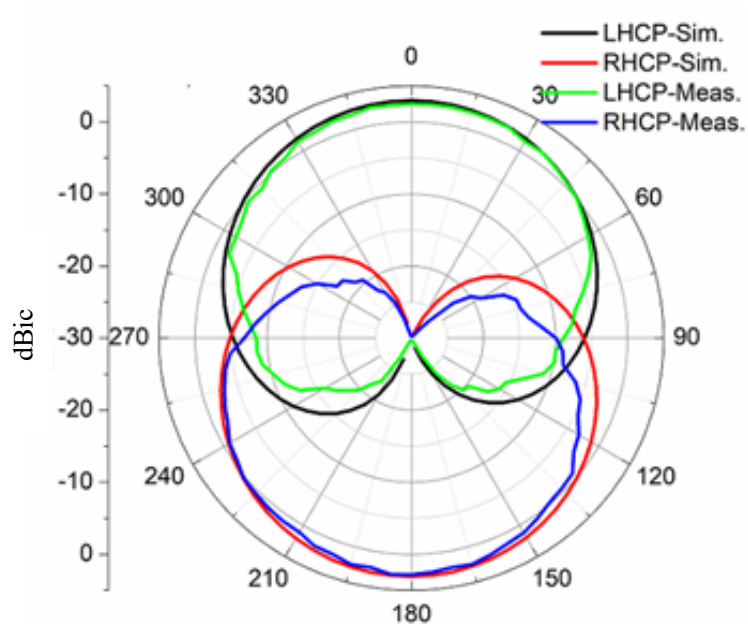

(b)

Fig. 19. Simulated and measured radiation patterns at $5.2 \mathrm{GHz}$ for $x z$ - and $y z$-plane.

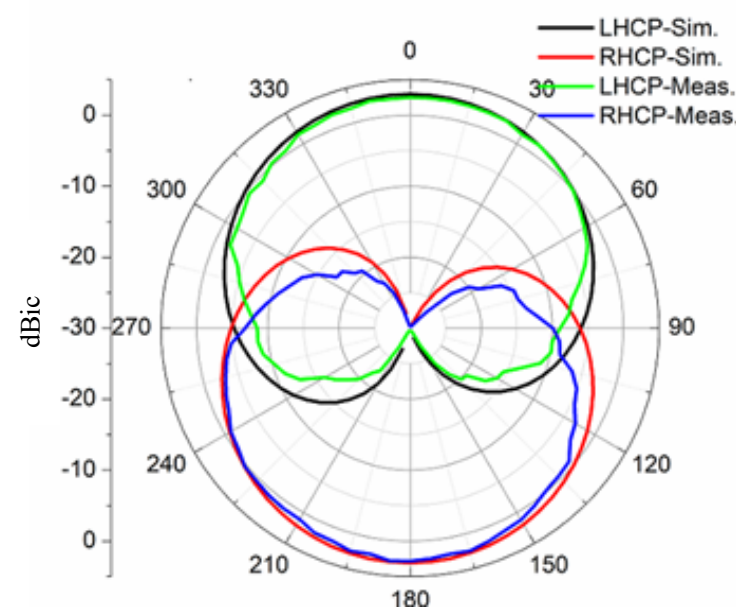

(a)

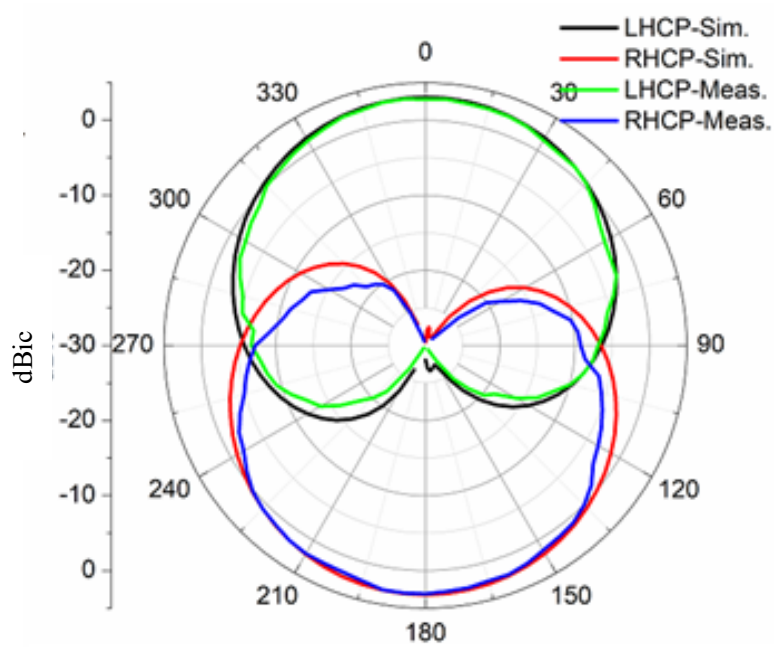

(b)

Fig. 20. Simulated and measured radiation patterns at $5.8 \mathrm{GHz}$ for $x z$ - and $y z$ plane.

\section{CONCLUSION}

This study has offered the design steps and experimental investigation of a square slot CPW fed wideband CP antenna. The offered antenna gives stable and steady radiation patterns with a wide-ranging $3-\mathrm{dB} A R B W$ of over and above $90^{\circ}$ in the whole frequency range of concern. The measured outcomes show that a wideband $I B W$ of $87.8 \%(3.6-9.0 \mathrm{GHz})$ and a wide $A R B W$ of $73.05 \%(4.2-9.0 \mathrm{GHz})$ can be achieved using this design. The measured radiation pattern of fabricated antenna provides an almost uniform radiation pattern for LHCP in the upper half-sphere and RHCP in the lower half-sphere in both $x z$-and $y z$-planes for the entire $A R W B$. The maximum efficiency and peak gain values are $88 \%$ and $4.4 \mathrm{dBic}$, respectively. Due to the low profile and compactness of the offered antenna, it may become the most suitable candidate for C-band wireless communication applications.

\section{ACKNOWLEDGMENT}

The authors are thankful to the Competitive Research Scheme by RTU (ATU) TEQIP III (project ID TEQIP-III/RTU(ATU)/CRS/201920/64) for supporting the present study.

\section{REFERENCES}

[1] G. Kumar and K. P. Ray, Broadband Microstrip Antenna. Artech House, Boston, 2003.

[2] Gunaram and V. Sharma, "Microstrip antenna - inception, progress and current-state of the art review", Recent Advances in Electrical \& Electronic Engineering, Vol. 13, No. 6, pp. 769-794, 2020. https://doi.org/10.2174/2352096513666200110151616

[3] S. Gao, Q. Luo and F. Zhu, Introduction to Circularly Polarized Antennas. Chapter 1, November 2013. https://doi.org/10.1002/9781118790526.ch1

[4] Gunaram, J. K. Deegwal and V. Sharma, "Dual band circular polarized printed dipole antenna for S and C band wireless applications", Progress in Electromagnetics Research C, Vol. 105, pp. 129-146, 2020. https://doi.org/10.2528/PIERC20050301

[5] M. Midya, S. Bhattacharjee and M. Mitra, "CPW-Fed dual-band dualsense circularly polarized antenna for Wi-Max application", Progress in Electromagnetics Research Letters, Vol. 81, pp. 113-120, 2019. https://doi.org/10.2528/PIERL18091306 
[6] V. Sharma, V. K. Saxena, K. B. Sharma and D. Bhatnagar, "Radiation performance of circularly polarized broadband gap coupled elliptical patch antenna, Frequenz, Vol. 66, No. 3, pp. 69-74, 2012 https://doi.org/10.1515/freq-2012-0018

[7] T. Jhajharia, V. Tiwari and D. Bhatnagar, "Polarisation reconfigurable dual-band circularly polarised patch antenna with defected ground plane for C-band wireless applications", IET Microwaves, Antennas \& Propagation, Vol. 13, No. 14, pp. 2551-2558, 2019. https://doi.org/10.1049/iet-map.2018.6214

[8] Ajay Kumar Dwivedi, Brijesh Mishra, Vivek Singh, Pramod Narayan Tripathi and Ashutosh Kumar Singh, "Design of a Compact CPW-Fed Monopole Antenna with Asymmetrical Hexagonal Slot Loaded Ground Structure for $\mathrm{C} / \mathrm{X} / \mathrm{Ku}$ Band Applications", Electrical, Control and Communication Engineering, Vol. 16, No. 1, 2020, pp. 15-22. https://doi.org/10.2478/ecce-2020-0003

[9] A. Birwal, S. Singh, B. Kumar Kanaujia and S. Kumar, "CPW-fed ultrawideband dual-sense circularly polarized slot antenna", Progress in Electromagnetics Research C, Vol. 94, pp. 219-231, 2019. https://doi.org/10.2528/PIERC19052005

[10] Nasimuddin, Y. S. Anjani and A. Alphones, "A wide-beam circularly polarized asymmetric-microstrip antenna," IEEE Transactions on Antennas and Propagation, Vol. 63, No. 8, pp. 3764-3768, Aug. 2015. https://doi.org/10.1109/TAP.2015.2438397

[11] S. Trinh-Van, Y. Yang, K. Y. Lee, Y. S. Kim and K. C. Hwang, "Bandwidth enhanced circularly polarized crescent-shaped slot antenna via circular-patch loading", Applied Sciences, Vol. 9, No. 6, pp. 1117 2019. https://doi.org/10.3390/app9061117

[12] T. Jhajharia, V. Tiwari, D. Bhatnagar, D. Yadav, S. Rawat, "A dual-band CP dual-orthogonal arms monopole antenna with slanting edge DGS for C-band wireless applications", AEU - International Journal of Electronics and Communications, Vol. 84, pp. 251-257, 2018. https://doi.org/10.1016/j.aeue.2017.12.005

[13] Y. Qin, X. Mo, R. Li, T. Wong and Y. Cui, "A broadband wide-beam circularly polarized antenna array for urban Macrocell base stations," IEEE Transactions on Antennas and Propagation, Vol. 67, No. 5, pp 3478-3483, May 2019. https://doi.org/10.1109/TAP.2019.2902706

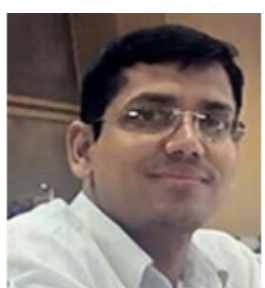

Vijay Sharma completed his UG, PG, and Doctora research in Physics at the University of Rajasthan, Jaipur (India) in 2000, 2002 and 2011, respectively. His research interest includes the design and development of compact size circular polarized antenna, wideband antenna with high gain for wireless communication and other applications.

He has more than 18 years of teaching and research experience. Currently, he is working as an Assistan Professor at the Department of Physics, Government Mahila Engineering College, Ajmer (India). He has authored more than 38 research articles in various reputed journals and conferences. He is a life member of the Indian Physics Association, Indian Association of Physics Teachers, and International Association for the Engineers. He is a reviewer of many prestigious journals, including Bentham Science, Electronics Letters, and IET MAP. Currently, he is working on two projects: (i) design and analysis of some novel patch antenna geometry for fifth-generation wireless $(5 \mathrm{G})$ communications and (ii) the design and development of patch antennas for modern-day IoT applications.

E-mail: phyvijay@gmail.com

ORCID iD: https://orcid.org/0000-0002-9571-5695
[14] S. Ravikanti and L. Anjaneyulu, "A Novel and Compact Circularly Polarized Antenna for 5G Wireless Local Area Network Application", Electrical, Control and Communication Engineering, Vol. 16, No. 1, 2020, pp. 44-50. https://doi.org/10.2478/ecce-2020-0007

[15] T. Jhajharia, V. Tiwari, D. Yadav, S. Rawat and D. Bhatnagar, "Wideband circularly polarised antenna with an asymmetric meandered-shaped monopole and defected ground structure for wireless communication," IET Microwaves, Antennas \& Propagation, Vol. 12, No. 9, pp. 1554 1558, 2018. https://doi.org/10.1049/iet-map.2018.0092

[16] G. Li and F. S. Zhang, "A compact wide beam circularly polarized antenna with wide impedance and axial ratio bandwidths" Int $J R F$ Microw Comput Aided Eng, Vol. 30, e22015, 2020. https://doi.org/10.1002/mmce.22015

[17] Y. D. Yan, Y. C. Jiao, Z. Weng and C. Zhang, "An umbrella-shaped broadband circularly polarized antenna with wide beamwidth for global navigation satellite systems applications", Microw Opt Technol Lett., Vol. 61, No. 11, pp. 2455-2462, 2019. https://doi.org/10.1002/mop.31917

[18] V. Sharma and T. Jhajharia, "Low profile CPW-fed compact square slot antenna with wide axial ratio bandwidth," in 2020 IEEE Microwave Theory and Techniques in Wireless Communications (MTTW), Riga, Latvia, 2020, pp. 86-90. https://doi.org/10.1109/MTTW51045.2020.9245064

[19] EM Simulation Software - CST Studio Suite. 2017.

[20] H.-D. Chen, "Broadband CPW-fed square slot antennas with a widened tuning stub," IEEE Transactions on Antennas and Propagation, Vol. 51, No. 8, pp. 1982-1986, 2003. https://doi.org/10.1109/TAP.2003.814747

[21] C. A. Balanis, Antenna Theory: Analysis and Design, $3^{\text {rd }}$ Edition. New Jersey: John Wiley \& Sons, Inc., 2005.

[22] J. Sze and C. Chang, "Circularly polarized square slot antenna with a pair of Inverted-L grounded strips", IEEE Antennas and Wireless Propagation Letters, Vol. 7, pp. 149-151, 2008. https://doi.org/10.1109/LAWP.2008.921341

[23] Jaiverdhan, A. Kumar, M. M. Sharma and R. P. Yadav, "Dual wideband circular polarized CPW-fed strip and slots loaded compact square slot antenna for wireless and satellite applications", AEU - International Journal of Electronics and Communications, Vol. 108, pp. 181-188, 2019. https://doi.org/10.1016/j.aeue.2019.06.027

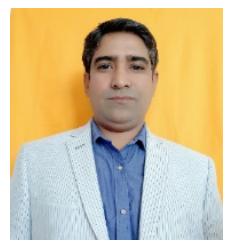

Tejpal Jhajharia completed his UG (Bachelor of Engineering) at the University of Rajasthan, Jaipur (India) in 2004, PG (M. Tech.) at the Malaviya National Institute of Technology Jaipur (India) in 2009, and Doctoral research in Electronics and Communication Engineering at the Manipal University Jaipur, Jaipur (India) in 2020. His research interest includes the design and development of circularly-polarized microstrip antennas, wideband antennas, high-frequency antennas for wireless communication, and digital signal processing. He has more than 14 years of teaching and research experience. Currently, he is working as an Assistant Professor at the Department of Electronics and Communication Engineering, Manipal University Jaipur, Jaipur (India). He has authored more than 15 research articles in various reputed journals and conferences. He is a reviewer of many prestigious journals, including Bentham Science, IET MAP, and Int. J. of Computer Aided Engineering and Technology. He is a member of IEEE, IEEE AP-S, and a life member of IETE.

E-mail: tej.pal@jaipur.manipal.edu

ORCID iD: https://orcid.org/0000-0002-0444-7438 